REVIEW

\title{
Management of vascular lesions using advanced laser technology
}

\author{
Christofer Tzermias ${ }^{*}$, Areti Eleftheriadi, Ioulia Gkiouzepaki
}

Intensive Quality (IQ) Dermatology, Athens, Greece

\begin{abstract}
One of the most widely used cutaneous applications of Light Amplification by Stimulated Emission of Radiation (laser) concerns the treatment of vascular lesions. During the past two decades, very significant advances in the application of laser technology in dermatology have occurred, with selective photothermolysis being the most important. This review focuses on the application of modern laser devices (Pulsed Dye Laser, or PDL; potassium titanyl phosphate laser, or KTP; diode laser; and neodymium-doped yttrium-aluminium-garnet laser, or Nd:YAG), as well as the combination of laser and photodynamic therapy (PDT) for the treatment of vascular lesions. In lar, both congenital (haemangiomas and port-wine stains) and acquired vascular lesions (facial and leg telangiectasias, rosacea, Poikiloderma of Civatte, spider angioma, pyogenic granuloma, and venous lakes) are discussed. The review of many recent research studies demonstrates that modern applications of lasers in dermatology constitute the finest method for the treatment of vascular lesions, combining the advantages of invasive therapy with the security offered by non-invasive therapy, while in certain cases they are the single and only choice for the treatment of these lesions.
\end{abstract}

Keywords: Vascular lesions; laser; PDL; Nd:YAG; PDT

Citation: Tzermias C, Eleftheriadi A, Gkiouzepaki I. Management of vascular lesions using advanced laser technology. J Surg Dermatol 2017; 2(T1): 115-129; http://dx.doi.org/10.18282/jsd. v2.it1.109.

*Correspondence to: Christofer Tzermias, 49, Vas. Sofias Avenue, Athens, Greece, dr.tzermias@ gmail.com.

Received: $15^{\text {th }}$ November 2016; Accepted: $2^{\text {nd }}$ January 2017; Published Online: $6^{\text {th }}$ April 2017

\section{Introduction}

Lasers were first used for the management and treatment of vascular lesions in the 1960s. During the past two decades, significant advances are evidenced, regarding laser application in dermatology and for the treatment of vascular lesions, in particular. An important breakthrough was the application of selective photothermolysis, the theory of which was first formulated by Anderson and Parish in 1983. According to this theory, when the laser beam contacts the vascular target, histologically selective vascular injury with coagulation is observed, together with vessel wall necrosis and perivascular collagen damage, while the associated thermal effects on the skin and the surrounding dermis are minimal ${ }^{[1]}$.

Today there are various types of lasers used in derma- tology. Pulsed dye laser (PDL) causes selective elimination of the vessel, leaving intact both normal epidermis and dermis. In addition, there are potassium titanyl phosphate laser (KTP), as well as infrared spectrum lasers such as alexandrite laser, diode laser, and neodymium-doped yttrium aluminium garnet laser (Nd:YAG). More recently, the combination of laser and photodynamic therapy (PDT) has also been employed for the treatment of vascular lesions.

The employment of lasers for the treatment of cutaneous vascular lesions constitutes one of their most popular applications. This review focuses on the use of lasers for the management of cutaneous vascular lesions, and discusses the data produced in recent research studies. For the purpose of this review, the categorisation of vascular lesions according to their time of onset-i.e. the distinction between congenital and acquired vascular

Copyright (C) 2017 Tzermias C, et al. This is an Open Access article distributed under the terms of the Creative Commons Attribution-NonCommercial 4.0 International License (http://creativecommons.org/licenses/by-nc/4.0/), permitting all non-commercial use, distribution, and reproduction in any medium, provided the original work is properly cited. 
lesions ${ }^{[2]}$, which can be managed with the use of lasers - will be used.

\section{Selective photothermolysis theory}

The theory of selective photothermolysis, initially introduced by Parrish and Anderson in $1983^{[1]}$, describes both the selective tissue damage as well as the minimum energy requirements for target destruction. More specifically, the theory of selective photothermolysis specifies that a chromophore may be targeted and damaged without causing significant injury to the surrounding tissues in the sense of a collateral damage. The variations in terms of wavelength (nanometres, or $\mathrm{nm}$ ), fluence (energy density, or $\mathrm{J} / \mathrm{cm}^{2}$ ), beam diameter (spot size), and pulse durations (ms) result in the controlled thermal injury of the target tissue and the alterations in terms of penetration depth ${ }^{[2]}$.

To achieve selective photothermolysis, four conditions should be fulfilled: (a) appropriate wavelength of the beam so as to be absorbed much more by the target chromophore than by the surrounding tissue and to achieve the deepest possible penetration, (b) adequate energy density of the beam so that to cause a non-reversible damage to the target, (c) pulse duration smaller than the thermal relaxation time (TRT), which is proportional to the size of the diameter of the chromophore-target, and (d) the largest possible beam diameter so that to achieve deeper penetration.

In the case of vascular lasers, the main chromophore-target is intravascular oxyhaemoglobin and, to a lesser extent, deoxyhaemoglobin and methemoglobin ${ }^{[3]}$. Haemoglobulin absorbs best in the blue, green, and yellow spectrums $(418,542$, and $577 \mathrm{~nm}$, respectively). It also presents an absorption peak in the near-infrared range $(700-1100 \mathrm{~nm})$. The challenge when treating vascular lesions is that melanin also shows a similar absorption profile at shorter wavelengths. Therefore, for patients with darker skin (Fitzpatrick skin types IV to VI), longer wavelengths should be preferred in order to avoid complications such as hyperpigmentation.

Fluence (energy per unit area) is inversely proportional to the fraction of light absorbed by tissue. The deeper in the dermis the target lies, the higher the required fluence will be. In addition, in cases where the chosen wavelength is only poorly absorbed by the target, high fluence is also necessary.

Pulse duration should strictly be shorter or close to the target's TRT. For example, the TRT for larger vessels such as leg veins will range in hundreds of milliseconds, whereas for facial telangiectasia will range in tens of milliseconds. Lastly, as far as the beam diameter is concerned, the larger the spot size, the deeper the penetration and the less scattering of the beam will be.

A 2004 publication noted the lack of comparative studies on laser efficacy/safety for the treatment of cutaneous vascular lesions ${ }^{[4]}$. Since then, more side-by-side studies have taken place. This article reviews up-to-date concepts on laser treatment of vascular lesions both in adults and children. It presents the most common vascular lesions amenable to laser treatment and highlights the keys in choosing the most efficient laser device for each case.

\section{Types of vascular lasers and energy-based devices}

Among the first lasers to be used were continuous wave (CW) lasers such as argon laser ${ }^{[5]}$. These laser devices were widely utilised for the treatment of cutaneous vascular lesions but, apart from their relatively poor effectiveness on treatment, another main preventive side effect was the higher risk of scarring due to the long exposure durations. Today, with the continuous technological advances, they are no longer useful, as they pose a high risk of adverse effects such as dyschromia and scarring $^{[2]}$. They have been replaced with quasi-CW mode lasers and pulsed laser systems that present lower risks and fewer side effects.

\section{Flash-pumped PDL}

The Flash-pumped PDL is the most commonly used laser for most types of vascular lesions. PDL emits a pulsed beam at $585 \mathrm{~nm}$ wavelength (yellow light). A rhodamine dye dissolved in a solvent is pumped by a flash lamp. PDL maintenance is demanding, requiring annual service and replacement of the lamp and dye if necessary. The machine has to be switched off at least once per day to allow dye circulation.

The first PDL emitted a wavelength of $577 \mathrm{~nm}$ with fixed pulse duration of $0.45 \mathrm{~ms}$. This short pulse duration, having had the small spot size, with high fluence as well as short wavelength and with limited depth penetration, produced very high complication rates including purpura and scarring. Current PDL emits at the spectrum of 585-600 nm with variable pulse durations, ranging from 0.45 to $40 \mathrm{~ms}$. The longer pulse durations match better the feeding vessel's size and at the same time allow epidermal cooling, hence reducing risk of side effects. Spot sizes are available in the range between 3 to $12 \mathrm{~mm}$ and maximal energy fluence, depending on spot size, of $40 \mathrm{~J} / \mathrm{cm}^{2}$. PDL is safe for children and infants. 


\section{Neodymium:yttrium-aluminium-garnet laser}

Neodymium:yttrium-aluminium-garnet (Nd:YAG) laser emits in the near-infrared range of the spectrum at 1064 $\mathrm{nm}$. The long wavelength enables deeper penetration while being much less absorbed by the competing chromophore-melanin. Therefore, Nd:YAG is the laser of choice for the treatment of vascular lesions of patients with darker skin types (Fitzpatrick IV to VI). It is also preferred for the treatment of deeper and resistant larger vessels. There is a relevant risk of scarring and blistering.

A spot selection $(3,5,7$, and $10 \mathrm{~mm})$, with variable pulse duration $(0.1-300 \mathrm{~ms})$ to adjust to different vessel diameters, is available. High fluences $\left(14 \mathrm{~J} / \mathrm{cm}^{2}\right.$ up to 300 $\mathrm{J} / \mathrm{cm}^{2}$ ) and optimal cooling systems to avoid pain or burning should theoretically be effective for the treatment of most vascular lesions. The clinical endpoint is the clearing of the vessel immediately after treatment or colour change on the vessels.

On Q-switched mode, Nd:YAG produces two wavelengths: one in the infrared range $(1064 \mathrm{~nm})$ and a second beam of $532 \mathrm{~nm}$ wavelength, which is useful for superficial skin lesions and which acts similarly to the KTP. This is done with the adjustment of a potassium titanyl phosphate crystal. All the parameters should be individualised and accordingly applied based on the skin type and the history and nature of the lesion.

\section{Potassium titanyl phosphate laser}

Potassium titanyl phosphate (KTP) lasers belong to the quasi-continuous lasers and emit at the $532 \mathrm{~nm}$ wavelength. Spots available are up to $5 \mathrm{~mm}$ and pulses durations range from $1-150 \mathrm{~ms}$. Fluences up to $240 \mathrm{~J} / \mathrm{cm}^{2}$ are available. The main restriction with KTP is that melanin is a strong competing chromophore along with haemoglobulin at this short wavelength. Therefore, KTP is only suitable for skin types I-III. KTP is mainly used for small facial telangiectasia.

\section{Broad-band light sources: Intense pulse light}

Intense pulse light (IPL) sources use a xenon flash lamp powered by a capacitor bank. IPL emit wavelengths between 515 and $1000 \mathrm{~nm}$. This polychromatic energy makes IPL versatile and useful for the management of multiple skin conditions, both vascular and pigmentation disorders. In addition, their large spot sizes make them efficient for the treatment of extensive lesions.

\section{Photodynamic therapy}

Photodynamic therapy (PDT) involves the exposure of skin to a light source after the effect of a photosensitising agent. The agent can be applied topically or be administered orally or intravenously. The photosensitiser, after being exposed to light, reacts with local oxygen and generates cytotoxic reactive oxygen species and subsequent tissue injury. The main benefit of PDT is that the low optical powers do not cause any epidermal injury, minimising risk of scarring and permitting treatment of all skin types.

\section{Vascular lesions}

Dermatologists encounter a wide range of cutaneous vascular lesions. These are divided into two categories: congenital and acquired. This categorisation is important for the initial assessment and the final choice of the treatment method. An overview of the most common types of congenital and acquired vascular lesions can be seen in Table $\mathbf{1 .}$

\section{Congenital vascular lesions}

Congenital vascular lesions include haemangiomas as well as port-wine stains (PWS). As far as the differential diagnosis among the congenital cutaneous vascular lesions is concerned, Table 2 presents briefly the differentiation elements between haemangiomas and $\mathrm{PWS}^{[6]}$.

Table 1.Vascular lesions

\begin{tabular}{ll}
\hline & Congenital vascular lesions \\
- & Infantile haemangiomas \\
Port-wine stain (PWS) \\
\hline Acquired vascular lesions \\
- $\quad$ Facial telangiectasia \\
- $\quad$ Rosacea telangiectasia \\
- $\quad$ Poikiloderma of Civatte \\
- $\quad$ Ppider angioma \\
Pyogenic granuloma \\
\hline
\end{tabular}


Table 2. Differential diagnosis of congenital vascular lesions

\begin{tabular}{|c|c|c|}
\hline Characteristics & Haemangiomas & Port-wine stains \\
\hline Present at birth & $30 \%$ & $100 \%$ \\
\hline Incidence by the age of 1 year & $10 \%-12 \%$ & $0.3 \%-0.5 \%$ \\
\hline Female: Male ratio & $3: 1$ & $1: 1$ \\
\hline Endothelial cell proliferation & Quick & Normal \\
\hline Clinical course & $\begin{array}{l}\text { Rapid growth far above the } \\
\text { normal development rate of the } \\
\text { infant } \\
\text { (Proliferation phase) }\end{array}$ & $\begin{array}{l}\text { Growth proportional to the rate } \\
\text { of normal development }\end{array}$ \\
\hline Prognosis & $\begin{array}{l}\text { Slow gradual involution, perfect } \\
\text { or imperfect } \\
\text { (Involution phase) }\end{array}$ & $\begin{array}{l}\text { No involution, } \\
\text { on the contrary, they worsen }\end{array}$ \\
\hline Localisation on the face or neck & $60 \%$ & $85 \%-90 \%$ \\
\hline Heredity & None & Multifactorial \\
\hline Complications & $\begin{array}{l}\text { - Ulceration, inflammation, bleed- } \\
\text { ing } \\
\text { - Obstructive phenomena e.g. con- } \\
\text { vergent amblyopia, and perma- } \\
\text { nent refractive abnormalities, } \\
\text { hearing, feeding, urination, defe- } \\
\text { cation problems, etc. }\end{array}$ & $\begin{array}{l}\text { - Glaucoma, seizures } \\
\text { - Tissue and/or bone hypertro- } \\
\text { phy }\end{array}$ \\
\hline
\end{tabular}

\section{Cutaneous haemangiomas}

Infantile haemangiomas (IH) are proliferating embryonal tumours, which can stem from placental tissue and are constituted by endothelial cells that hyperproliferate. Haemangiomas are the most common benign tumours in childhood, with their prevalence estimated to be up to $10 \%-12 \%$ in Caucasian infants, whereas they are less common in African and Asian children. The incidence is three times higher in females and especially in premature infants, as both the lower gestational age and the lower birth weight are associated with the development of the tumour ${ }^{[3]}$.

The characteristic feature of haemangiomas is an early and rapid growth proliferation phase, followed by a stabilisation phase and a slow spontaneous regression phase, while during proliferative phase, $80 \%$ of all haemangiomas is doubled compared to their initial size ${ }^{[7]}$. In addition to this, these lesions may cause functional disorders, haemorrhage, and ulceration, while they may also lead to a secondary infection and aesthetic deformity ${ }^{[2,8-10]}$.

Regarding the treatment of infantile haemangiomas, the optimal choice may depend on many factors, which should be taken into consideration by the dermatologist.
Among these factors are the anatomic location; the size, the depth, the phase of the lesion; the age of the patient; the physician's experience; as well as the availability of a particular therapeutic approach ${ }^{[11-15]}$. It is also very important to inform the parents that $90 \%$ of haemangiomas will involute slowly after the age of 1 and may completely regress by the age of 9 . Therefore, many parents may choose to wait and see how the lesion will progress.

In cases where treatment is decided, however, argon laser was among the first lasers to be used in the past with good results but it caused increased risk of scarring due to exposure to continuous wave ${ }^{[16,17]}$. Nowadays, the most widely used laser for the treatment of infantile haemangiomas is PDL; less often, both Nd:YAG and diode lasers are also used ${ }^{[18,19]}$. PDL is the most commonly studied laser type for $\mathrm{IH}^{[20]}$, whereas $\mathrm{Nd}$ :YAG application is nowadays receiving a lot of attention.

According to a recent retrospective study conducted in New York, the use of 595-nm long-pulsed PDL (LPDL) with dynamic epidermal cooling was found to be particularly effective. Specifically, a total number of 90 infants were included with a median age of 3.0 months with a total number of 105 haemangiomas, and were treated 
using this particular laser device. The results showed that complete or near-complete clearance was achieved for $81 \%$ of the haemangiomas in terms of colour and $64 \%$ in terms of thickness ${ }^{[21]}$.

Similar results were also found by a study conducted in Korea, in which a total number of 239 patients with skin types II-V participated and of whom, 37 patients had haemangiomas, and the same variable-pulse PDL method was used. More specifically, among the patients with haemangioma, the male-female ratio was 1.0:3.1; and for more than half of them (54.1\%), good to excellent responses were achieved. Variable-pulse PDL proved effective and safe for darker skin types. As noted by the investigators, the best clinical response was observed in superficial haemangiomas in comparison to deep haemangiomas. Moreover, the lesions of younger patients responded more favourably than those of older patients $^{[22]}$.

In addition to these observations, a randomised controlled trial, in which 52 infants aged 1-3 months participated, showed that LPDL is more effective and significantly safer than PDL. In the aforementioned study, the infants were divided into two groups: one treated with PDL $(n=26)$ and the other $(n=26)$ treated with LPDL. In both occasions, the laser was combined with the use of epidermal cooling devices. Each group received treatment every four weeks until lesion clearance, and the outcome was assessed at the age of one year old. The assessment included clearance rate, time period of maximum proliferation, and complications. According to the results, at final assessment, 54\% of the patients following treatment using the PDL showed complete clearance or minimal residual signs, while the corresponding percentage for the group of children following treatment with the LPDL was $64 \%$. Although this difference was not statistically significant, the group treated with PDL had significantly more hypopigmentation $(3.12 \%$ vs. $8.31 \% ; p=0.001)$, more hyperpigmentation $(2.8 \% v s$. $4.15 \% ; p=0.005)$, and more textural changes $(1.4 \% v s$. $6.23 \% ; p=0.001)$. Finally, the average time period of maximum proliferation in the LPDL group was significantly shorter ${ }^{[23]}$.

Recently, a comparison study was carried out in order to identify the earlier regression, the prevention of further proliferation, and the achievement of a better cosmetic outcome using PDL treatment in comparison to observation only ("wait-and-see approach"). A total number of 22 infants participated in the study, aged up to six months old. The investigators concluded that there were statistically significant differences in terms of the haemangioma's red colour and the final cosmetic outcome at 12 months in the group of infants treated with
PDL as compared to the "wait-and-see" group ${ }^{[24]}$.

As far as the long-pulsed ND:YAG Laser (1064 nm) is concerned, it seems that this type of laser is a safe and efficacious treatment for infantile haemangiomas, especially for older patients and superficial haemangiomas ${ }^{[25]}$. Combination therapy with PDL and Nd:YAG laser was also proved safe and effective in a German study ${ }^{[26]}$.

The use of endolesional diode laser has also been shown to be effective in the treatment of infantile haemangiomas. A study conducted with the participation of a total number of 250 children, among whom 160 had haemangiomas, showed that the $980 \mathrm{~nm}$ diode laser used endolesionally is useful and effective in terms of cosmetic outcome and lesion clearance. Furthermore, among all paediatric patients of the study, only 38 required a second treatment session in order to achieve successful treatment, irrespective of their type of lesion ${ }^{[19]}$. Diode laser seems also to be useful for the treatment of remaining telangiectasia following haemangioma involution ${ }^{[27]}$.

Finally, according to a retrospective study, the combination of PDL and propranolol resulted in better clearance of infantile haemangiomas, using a smaller total dose of propranolol to achieve almost complete clearance in comparison to the treatment method of propranolol followed by PDL or using propranolol alone ${ }^{[28]}$.

\section{Port-wine stains}

Port-wine stains (PWS) are the most common congenital vascular malformation with a prevalence of $3 \%{ }^{[29]}$. PWS indicate capillary extension and histopathological deformations. A number of vessels dilate, reaching a diameter of 10 to $150 \mu \mathrm{m}$, involving predominantly the papillary or the upper reticular layer of the dermis at a depth of 300 to $600 \mu \mathrm{m}^{[30,31]}$.

The main difference between PWS and haemangiomas is that PWS have persistent pathological changes with no tendency to resolve with ageing. Therefore, it is recommended that PWS are treated as early as possible due to the probability of greater aesthetic disfigurement as well as the possibility of great psychological distress for the patient, usually a child at school age.

Argon laser was one of the first lasers to be applied on cutaneous lesions with a 488-514-nm wavelength that was well absorbed by oxyhaemoglobulin. However, the cutaneous wavelength was responsible for increased risk of side effects such as scarring and dyspigmentation $^{[32]}$.

During the past two decades, the use of lasers for the treatment of PWS has been extensively studied, and it has been found that PDL constitutes a highly effective and safe method as compared to other methods, due to the fact that the laser beam is only absorbed by the 
vessels, resulting in their selective damage and leaving the surrounding tissues intact. PDL was firstly developed for the treatment of PWS and for many years it has been the treatment of choice $e^{[8,10,33]}$, since it results in a better outcome as compared to Intense Pulsed Light (IPL) ${ }^{[34]}$. However, the more mature (hypertrophic and nodular) PWS usually respond less adequately to treatment ${ }^{[2,8]}$. These are mostly observed in older patients and their treatment may be particularly difficult in many cases due to the greater depth of the vascular lesion ${ }^{[35,36]}$.

The treatment of PWS using lasers is more effective when conducted during the first year after birth, which can partly be explained by the fact that the infant's skin is thinner, allowing greater penetration of the la$\operatorname{ser}^{[37]}$. During the subsequent stages of PWS's development, treatment is not effective and sometimes resistance to treatment is observed. In such cases, the application of lasers at longer wavelengths and pulse durations has been studied ${ }^{[38]}$.

As far as hypertrophic PWS previously resistant to PDL treatment are concerned, the use of long-pulsed alexandrite laser (LPPAL) $(755 \mathrm{~nm})$ has been proven useful when used alone ${ }^{[39]}$ or in combination with $\mathrm{PDL}^{[40]}$. A relative risk of depigmentation when using LPPAL has been noted. In the case of concurrent use of PDL and LPPAL, a better outcome is achieved in less time and the reduction in terms of lesion colour is more profound without increasing the number of adverse events or complications ${ }^{[40]}$.

In a side-by-side study, PDL and long-pulse Nd:YAG laser $(1064 \mathrm{~nm})$ were compared in regard to PWS treatment. A total number of 17 patients with PWS participated and it was shown that Nd:YAG is as effective as PDL when used at minimum purpura dose (MPD) ${ }^{[41]}$. When MPD is exceeded, the risks of side effects also seem to increase.

A further study with 25 participants supported the combined use of PDL (595 nm) and Nd:YAG (1064 $\mathrm{nm}$ ), concluding that the aforementioned combination constitutes an effective treatment method for persistent PWS which do not respond to PDL treatment alone. Its adverse events were limited to temporary erythema, oedema, and purpura to a much lesser extent ${ }^{[9]}$. Nodular elements of PWS also seem to respond better to the concurrent treatment with PDL and Nd:YAG laser as the longer wavelength enables deeper penetration ${ }^{[42]}$.

According to a recent study, the effectiveness of Nd:YAG laser (1064 nm) could be further improved by a potential optimisation of its effect on PWS. Experiments in albino rats, in which PEG-modified gold nanorods were intravenously injected, proved light absorbance to the laser by the blood to be significantly enhanced, thus addressing one of the method's limitations ${ }^{[43]}$.

Lastly, a study in 2016 looked into the histological differences between PWS of lateral and central face, aiming to explain why lateral facial PWS respond better to PDL than central facial PWS do. Biopsy results showed that vessels in the lateral regions were mainly located in the papillary dermis, whereas in the central regions they tend to expand deeper and run through the dermis into the subcutaneous tissue ${ }^{[44]}$. In general, however, PWS on the face tend to respond better to the treatment than lesions on the rest of the body ${ }^{[45]}$.

As a whole, the treatment of congenital vascular lesions using laser has been proven to be effective when initiated during the first year of life, something that is partially explained by the fact that the infant's skin is thinner and better penetration of the laser beam within the lesion is achieved ${ }^{[37]}$. PDL remains the first treatment of choice for most patients with PWS, with desired clinical endpoint being light purpura presented immediately or within a few minutes post-treatment. The presentation, on the contrary, of a steel-grey post-operative purpura may be indicating that the fluence of treatment was higher than appropriate and, as a result, the risk of scarring or blistering is increased.

Regarding the expectations that the patients should have, both for PWS and haemangiomas, in relation to treatment success, usually six or more treatment sessions are required within a period of two years to achieve significant clinical outcome. For patients with PWS at specific spots on their body, such as the upper lip, more treatment sessions may be required while complete clearance may not be achieved.

\section{Photodynamic therapy and cutaneous PWS}

In addition to the use of lasers, the application of photodynamic therapy (PDT) has also been studied for the treatment of PWS. According to recent studies, the combination of PDL and PDT using the topical photosensitising agent 5-aminolevulinic acid (5-ALA) seems to be effective in the treatment of PWS ${ }^{[42,46,47]}$.

PDT involves the administration of a photosensitising agent and the subsequent exposure to light at a specific wavelength, resulting in the production of reactive oxygen species (ROS), which in turn leads to cytotoxic effects due to the oxidative damage of the surrounding cellular structures ${ }^{[48]}$. These cytotoxic ROS, a product of the reaction of the activated photosensitiser with local oxygen, can induce highly localised cellular or tissue damage ${ }^{[49]}$.

Recently, the application of 5-ALA followed by 595- 
nm PDL irradiation was assessed for the treatment of recalcitrant PWS. More than half of the patients $(65.71 \%)$ showed mild to moderate clinical improvement after three treatment sessions, while patients' discomfort over the entire course of treatment was similar to that of previous treatments with PDL alone ${ }^{[46]}$. A significant number of large research studies have been conducted in China, in which PDT was used for the treatment of cutaneous lesions. In a retrospective analysis, the data of 238 patients with PWS, who received treatment with photocarcinorin-mediated PDT using a copper vapour laser were presented. Following two to four treatment sessions using PDT, almost one-third of the patients (29\%) showed particularly good outcome and slightly more patients $(32 \%)$ showed good outcome, while poor response was evident for only $3 \%$ of the patients ${ }^{[50]}$.

PDT effectiveness was also demonstrated in another longitudinal retrospective study, in which the data of 1,385 patients with PWS who followed PDT for the treatment of their vascular lesions were examined. The investigators concluded that PDT is an effective treatment method for all types of PWS. Usually, more than one treatment sessions are required to achieve a better cosmetic outcome, yet after only one PDT treatment session, almost half of the patients had an excellent or very good outcome and fewer than $10 \%$ of them had just a good outcome ${ }^{[51]}$.

Moreover, in a side-by-side comparison of PDT and PDL for the treatment of PWS, it was shown that PDT is at least as effective and safe as PDL, or even superior in some cases, for the treatment of certain types of PWS ${ }^{[31]}$. Similar results were reported in another study, in which the investigators concluded that the combination of PDT (benzoporphyrin derivative monoacid ring A photosensitizer with 576-nm light) and PDL for the treatment of PWS is effective and contributes to the reduction of the total number of treatment sessions, while the number of adverse events, such as scarring, is also reduced ${ }^{[52]}$.

Recommendations regarding the use of the various lasers in the treatment of congenital vascular lesions are summarised in Table 3.

\section{Acquired vascular lesions}

Acquired vascular lesions that can be managed using lasers are classified into flat and papular. Among the flat vascular lesions, idiopathic telangiectasia, telangiectatic rosacea, linear telangiectasia of face-nose, Poikiloderma of Civatte, as well as leg telangiectasias are included. Among papular vascular lesions, spider angiomas, cherry angiomas, and angiokeratomas are included. In the following sections, the application of lasers for the treatment of certain acquired vascular lesions is discussed, while a summary of treatment recommendations for each condition is, soon thereafter, provided in Table 4.

\section{Telangiectasias}

Telangiectasias are enlarged capillaries in the skin, visible to the naked eye, which usually occur on areas of the face and lower extremities. These superficial vessels have usually a diameter between 0.1 and $1 \mathrm{~mm}$, and represent a dilated venule, capillary or arteriole. They are located underneath the epidermis and their colour usually varies from dark cyan to bright red. Depending on their appearance, telangiectasias are characterised as simple or linear, arborising, spider or star, punctiform, and papular.

Facial telangiectasias usually emerge on the central and lateral areas of the face ${ }^{[2]}$. Their aetiology and pathogenesis may be the result of various factors, including genetic predisposition, presence of other diseases, chronic sun exposure, surgical or physical trauma, corticosteroid use, pregnancy, oestrogen ingestion, etc. For the management of face and neck telangiectasia, irrespective of its type and extension, there are many advanced lasers operationally based on the selective photothermolysis principle (LPDL, KTP $532 \mathrm{~nm}$, long-pulsed Nd:YAG), which ensure effectiveness.

Classic PDL has been extensively used for arborising telangiectasias, providing particularly good results in comparison to other light sources, but causing purpura reaction. In order to achieve treatment without inducing purpura reaction, the use of multiple applications of LPDL is required ${ }^{[53]}$. In a randomised controlled trial in which 39 patients participated, it was shown that LPDL was more effective than IPL in terms of vessel clearance. Apart from this, patients reported that they preferred this type of PDL as it was both more effective and caused less pain during the treatment session ${ }^{[54]}$.

As far as KTP $(532 \mathrm{~nm})$ is concerned, it has been suggested that it is preferable in more distinct cases of linear telangiectasias. In a retrospective study, data of 49 patients with facial telangiectasia were examined and, following the treatment and the follow-up phases, complete or almost complete clearance was achieved in $90 \%$ of the patients. Based on the findings, the investigators concluded that this type of laser provides a safe and effective treatment of common superficial vascular lesions in patients with skin types I-III according to the Fitzpatrick scale ${ }^{[55]}$.

Interesting findings were also yielded by another retrospective study that included the data of a large number of patients followed-up for three years, in relation to the treatment of superficial vascular lesions using Nd:YAG laser $(1064 \mathrm{~nm})$. Among 130 patients with facial telangiectasia who completed the study, 125 of them (97\%) 
Table 3. Recommendations for the use of lasers for treatment of congenital vascular lesions

\begin{tabular}{|c|c|c|}
\hline Indication & Lasers & Remark \\
\hline Infantile haemangioma & $\begin{array}{l}\text { PDL, Nd:YAG, } \\
\text { diode laser, IPL }\end{array}$ & $\begin{array}{l}\text { - Involution noted at } 90 \% \text { of cases by the age of } 9 \\
\text { years old. } \\
\text { - } \quad \text { PDL is the treatment of choice. } \\
\text { - } \quad \text { Deeper lesions: Nd:YAG. }\end{array}$ \\
\hline PWS & $\begin{array}{l}\text { PDL, IPL, Nd:YAG, } \\
\text { LPPAL, PDT }\end{array}$ & $\begin{array}{l}\text { PDL is the most commonly used laser. Clinical } \\
\text { endpoint: purpura. } \\
\text { - Deeper and popular lesions do not respond well } \\
\text { to PDL. } \\
\text { - Nd:YAG is better suited for deeper lesions. } \\
\text { - Combination treatments should be considered in } \\
\text { - } \\
\text { PDistant cases. }\end{array}$ \\
\hline
\end{tabular}

Table 4. Summary of recommendations for treatment of acquired vascular lesions

\begin{tabular}{|c|c|c|}
\hline Indications & Lasers & Remarks \\
\hline Facial telangiectasia & $\begin{array}{l}\text { PDL, LPDL, IPL, KTP, } \\
\text { Nd:YAG }\end{array}$ & $\begin{array}{l}\text { - } \\
\text { - } \\
\text { - } \\
\text { KTP is is the most commonly used laser. } \\
\text { types. Caution with periorbital area. }\end{array}$ \\
\hline Leg telangiectasia & PDL, Nd:YAG & - $\quad \mathrm{Nd}$ :YAG is the treatment of choice. \\
\hline Rosacea & PDL, LPDL, IPL & $\begin{array}{l}\text { - LPDL is the treatment of choice. } \\
\text { - IPL: shorter "downtime" after treatment. }\end{array}$ \\
\hline Poikiloderma of Civatte & $\begin{array}{l}\text { KTP, PDL, Ablative Frac- } \\
\text { tional Lasers }\end{array}$ & $\begin{array}{l}\text { - Extra caution due to mixed features of tel- } \\
\text { angiectasia and hyperpigmentation. }\end{array}$ \\
\hline Spider angioma & PDL, Nd:YAG KTP & - $\quad$ PDL is the treatment of choice. \\
\hline Pyogenic granuloma & PDL, Nd:YAG, $\mathrm{CO}_{2}$ & - Increased risk of recurrence. \\
\hline Venous lake & $\begin{array}{l}\text { Nd:YAG, PDL, diode } \\
\text { laser, KTP }\end{array}$ & - $\quad$ Nd:YAG shows better results than PDL \\
\hline
\end{tabular}

showed significant improvement or complete clearance. However, this method is not recommended to be the first choice for facial telangiectasia, if vessels are not so deeply located. In the same study, it was also shown that among 99 patients with telangiectasia of the lower extremities who completed the study, 80 of them $(80.8 \%)$ showed significant improvement or complete clearance $^{[56]}$.
Finally, it is important to acknowledge the results of a recent study, which intended to assess the effectiveness and safety of a micropulse $1064 \mathrm{~nm} \mathrm{Nd:YAG} \mathrm{laser} \mathrm{for}$ the treatment of facial telangiectasias. A total number of 20 patients participated in the study, and their status was assessed following the completion of two treatment sessions using the aforementioned laser device. According to the assessment by an independent researcher, satisfac- 
tory clearance was achieved in $75 \%$ of patients and complete clearance was evident in as many as $10 \%$, while no patient was reported as having no clearance at all, or worsening or experiencing adverse events. Therefore, the investigators concluded that micropulse $1064 \mathrm{~nm}$ Nd:YAG laser is both safe and effective for the treatment of facial telangiectasia ${ }^{[57]}$.

As far as the treatment of telangiectasias of the lower extremities using Nd:YAG laser is concerned, a model has been suggested, in accordance with the best treatment outcome achieved using a range of moderate fluences $\left(100-200 \mathrm{~J} / \mathrm{cm}^{2}\right)$ and pulse durations between 10 and $100 \mathrm{~ms}$, in order to reduce excess dermis heating and pain ${ }^{[58]}$. Similar conclusions were reached in a recent study, according to which multiple treatment sessions, spaced 8 to 12 weeks apart, are necessary to reduce the colour and the size of the lesion, as well as to improve the contour of the skin with minimal side effects. Commonly, complete clearance of smaller lesions is achieved, while the size of greater venous malformation is reduced following the application of many treatment sessions using Nd:YAG laser ${ }^{[59]}$.

Srinivas and Kumaresan suggested that the best treatment option for telangiectasias of the lower extremities is achieved with $1064 \mathrm{~nm} \mathrm{Nd:YAG} \mathrm{laser,} \mathrm{as} \mathrm{its} \mathrm{leads}$ to in-depth penetration $(5-6 \mathrm{~mm})$, reaching deeply located vessels such as these characterising this particular condition ${ }^{[60]}$. The use of this laser device was also proposed by other researchers for the treatment of deeper vascular lesions, who also underlined that to avoid overheating of the skin and textural changes, the use of a cooling devise is necessary ${ }^{[6]]}$. The Nd:YAG laser is also a treatment of choice for telangiectasia of darker skin (Fitzpatrick IV-V), as the long wavelength enables deep penetration but minimum absorbance by mela$\operatorname{nin}^{[62]}$.

In general, the basic principles for laser application on linear or arborising telangiectasias concern the targeting of the vessel (vessel tracing method), the use of the appropriate beam diameter (seeking to achieve deeper penetration and reduce scattering), and the use of variable pulse range depending on vessels' size. In addition to these, the appropriate energy density should be applied to achieve irreversible damage of the target, which is determined by the skin phototype, the application, and the type of cooling device. The cooling device should be flexible and allow continuous visual contact as well as the presentation of the end-point. The end-point for vessels of small diameter relates to the direct clearance of thin telangiectasias and the immediate contraction of their wall. As far as the larger vessels are concerned, with a diameter of more than $0.3 \mathrm{~mm}$, the end-point relates to the immediate presence of intravascular coagulation, which is detected through palpation. Conclusively, one to three treatment sessions are usually required for the treatment of telangiectasias, while using the appropriate laser.

\section{Rosacea}

Rosacea is a chronic rash that is usually located in the midline of the face (nose, cheeks, forehead, periorbital, and chin), in which papules and crusts appear on red or erythematous skin. As the condition progresses, small vascular disorders of the skin may appear and eventually the sebaceous glands of the nose may swell, leading to malformations (rhinophyma). The condition is usual, especially in middle-aged persons from southern Europe. Women are affected more than men. According to many research studies, long-pulsed $595 \mathrm{~nm}$ PDL constitutes an effective method for the treatment of this condition, as well as the associated erythema and telangiectasia, with minimal adverse events and no long-term complications $^{[63,64]}$.

In one study, long-pulsed $595 \mathrm{~nm}$ PDL was used for the treatment of 20 patients with rosacea. Assessment was carried out using a scale from 0 to 6 , in which 6 represented the most severe cases. A mean score of 1.4 was observed at the end of the treatment, showing a statistically significant reduction. The investigators concluded that this particular type of laser has very good results in the treatment of rosacea, while its safety profile is as favourable as the PDLs of older technology ${ }^{[63]}$. Similar were the results in another study, where LPDL was used for the treatment of rosacea-associated telangiectasia and no significant purpura reaction was observed after treatment ${ }^{[65]}$.

Positive results have also been reported in relation to quality of life improvement for patients with erythematotelangiectatic rosacea who followed treatment using PDL. Specifically, a study employed the Dermatology Life Quality Index (DLQI), which was completed by the patients at the beginning and at the end of treatment. The results confirmed the statistically significant difference in the quality of life for all patients between baseline and after three treatment sessions when the final evaluation was recorded ${ }^{[64]}$. Similar results were demonstrated by Shim and Abdullah, through another similar study of patients with erythematotelangiectatic rosacea, who completed the DLQI. After three treatment sessions, the difference in terms of quality of life, as assessed by patients at the beginning and at the end of treatment, was statistically significant, with a better score after treatment ${ }^{[66]}$. Lastly, IPL has also been proven safe and effective for treatment of rosacea-related erythema and 
increased blood flow, as demonstrated by scanning laser doppler ${ }^{[67]}$.

\section{Poikiloderma of Civatte}

Poikiloderma of Civatte is a common condition that mostly affects women, particularly those with history of cumulative sun exposure. The sides of the neck are affected, causing erythema, diffuse telangiectasia combined with hyperpigmentation, and reticular wrinkling or even atrophy. Treatment may be achieved using a single or combinations of various types of laser, including KTP and PDL, to restore both the natural colour and the texture of the skin. Nevertheless, complete clearance of this condition may be challenging, while certain adverse events have also been reported, such as hypopigmentation and erythema above normal levels ${ }^{[60,68]}$.

In a study including 8 patients, most of whom were women, $585 \mathrm{~nm}$ PDL was used at a constant pulse duration of $450 \mu \mathrm{s}$. The investigators concluded that the result was good in terms of vascular lesion clearance. Nevertheless, 6 of the patients who followed treatment using a fluency between 5 and $7 \mathrm{~J} / \mathrm{cm}^{2}$ reported severe depigmentation 4 to 11 months after treatment completion, something that was not the case for those who followed treatment using a lower fluency between 3.5 and $5.5 \mathrm{~J} / \mathrm{cm}^{2}$. Therefore, PDL for the treatment of Poikiloderma of Civatte should be carefully applied, while further studies are needed to further evaluate the best method of application ${ }^{[69]}$. As mentioned in the recent guidelines by the European Society for Laser Dermatology (ESLD), special attention should be given in areas with hyperpigmentation, as well as in areas prone to scarring such as the anterior chest or neck ${ }^{[2]}$.

Lastly, a recent study among Caucasians patients showed good results in the treatment of both the vascular and the hyperpigmentation components of Poikiloderma of Civatte with ablative fractional laser resurfacing, which was accompanied by significant changes of skin texture and laxity ${ }^{[70]}$.

\section{Spider angiomas}

The use of various lasers has also been studied in relation to the treatment of smaller cutaneous vascular lesions such as the spider angioma. A characteristic of spider angiomas is their "elevated" papular central part, from which capillaries radiate outwards and gradually expand like a spider's web. It is a common condition in children but it may also appear in adults following pregnancy or on the background of liver disease.

The results of a retrospective study, in which the data of 58 patients with spider angiomas were examined, showed that $98 \%$ showed complete or almost complete clearance at the end of the treatment with KTP 532 $\mathrm{nm}$ and follow-up periods ${ }^{[55]}$. Moreover, PDL (595 nm) is also suggested for the treatment of spider angiomas, although it is noted that a number of treatment sessions are necessary ${ }^{[71]}$. Furthermore, in a prospective study, carried out in the United Kingdom with the participation of a total number of 201 patients with spider angiomas, it was found that lesion clearance occurred in $95 \%$ of them regardless of anatomic site. An average number of 1.84 treatment sessions using PDL were required, with a maximum number of 7 treatment sessions for a small number of patients, while for larger lesions, more treatment sessions were necessary ${ }^{[72]}$. Lastly, the successful employment of $1064 \mathrm{~nm}$ Nd:YAG laser has also been reported. In a follow-up study of 3 years, all 26 patients with spider angiomas were treated and experienced significant clearance with minimal pain, although the results were less encouraging in the instance of neck and hand areas ${ }^{[56]}$.

\section{Pyogenic granulomas}

A pyogenic granuloma, also known as lobular capillary haemangioma, is a common benign tumour of the skin and mucous membranes, characterised histologically by great accumulation of capillary blood vessels, which are surrounded by connective tissue and filtered by inflammatory cells ${ }^{[73]}$. Bleeding is also very common, even in cases of minor injury, while many times they emerge during pregnancy or following injury ${ }^{[74]}$.

Both $585 \mathrm{~nm}$ PDL and Nd:YAG lasers have been used for the treatment of pyogenic granulomas. As far as the use of PDL is concerned, the results of a study, in which 18 patients with symptomatic pyogenic granulomas at different parts of their body participated, indicate that it leads to effective treatment for the majority of patients. In particular, $88.9 \%$ of the patients demonstrated both symptomatic and clinical clearance of the lesions, with excellent cosmetic results after treatment ${ }^{[75]}$.

In a more recent retrospective study, the application of $\mathrm{Nd}$ :YAG laser for the treatment of pyogenic granulomas was tested. In this study, the data of 25 patients were examined and it became evident that the application of Nd:YAG laser (1-14 pulses, $100-130 \mathrm{~J} / \mathrm{cm}^{2}$ ) was effective in clearing these lesions in the majority of patients $^{[76]}$.

Apart from PDL and Nd:YAG lasers though, $\mathrm{CO}_{2}$ laser is also applied for the treatment of pyogenic granulomas. A recent study has reported successful and safe $\mathrm{CO}_{2}$ laser-assisted surgical excision of a pyogenic granuloma from the oral cavity of a pregnant woman with- 
out complications ${ }^{[77]}$. More importantly, a 10 -year retrospective study comparing the surgical removal of pyogenic granulomas, with either the classical method followed by suture, or with employment of a $\mathrm{CO}_{2}$ laser, concluded that the latter, should be the first-choice treatment for the ablation of pyogenic granulomas, as its recurrence rate was zero. Although, researchers were aware of recurrence issues reported in past studies, they considered those containable with proper decisionmaking ${ }^{[78]}$.

\section{Venous lakes}

Venous lakes are a form of senile angioma, which usually occurs on the face, lips, and ears of elderly patients. Histologically, venous lakes consist of greatly dilated, thin-walled venules without the proliferation of vascular tissue of the true angioma.

Among the first choices of laser devices for the treatment of venous lakes are both KTP and Nd:YAG lasers, as mentioned in the recent guidelines by the European Society for Laser Dermatology (ESLD) ${ }^{[2]}$.

A study, in which 35 patients with venous lakes were included, showed that following only one treatment session, complete clearance of the lesion was observed in $94 \%$ of the patients and no relevant complications were reported. The investigators concluded that long-pulsed $\mathrm{Nd}$ :YAG laser is highly effective for the treatment of venous lakes of the lips and cheeks ${ }^{[79]}$.

The combination of $595 \mathrm{~nm}$ PDL and $1064 \mathrm{~nm}$ Nd:YAG laser has also been found to be effective. More specifically, in a study with the participation of 30 patients, the degree of resolution of a total number of 39 venous lakes was assessed. The treatment was initially carried out using PDL (at $20 \mathrm{~ms}$ and $10 \mathrm{~J} / \mathrm{cm}^{2}$ ) followed by Nd:YAG laser (at $20 \mathrm{~ms}$ and $70 \mathrm{~J} / \mathrm{cm}^{2}$ ). The investigators reported complete clearance of 38 lesions (95\%) and no post-treatment complications, with the exception of one patient who had a small scar. Therefore, they concluded that the combined application of both of the aforementioned lasers provide a safe, fast, and effective option in the treatment of venous lakes ${ }^{[80]}$.

Finally, effective clearance of venous lakes may also be achieved using diode lasers. More specifically, in a recent study, in which 17 patients with venous lakes of the lips participated, $808 \mathrm{~nm}$ diode laser was used for treatment. The results showed that even after one single treatment session, all lesions were successfully treated. Healing was achieved after approximately two to three weeks, and none of the patients experienced complications, while post-operative discomfort and scarring were not present or minimal ${ }^{[81]}$.

\section{Conclusion}

The present literature review of recent research articles, regarding laser use for the management of cutaneous vascular lesions, proposes that successful ment can be achieved through the application of the various available laser devices. It is the authors' opinion that PDL is the most frequently used laser at the moment for the treatment of vascular lesions, offering a wide range of treatment applications. In general, with all current available equipment, vascular lesions can be satisfactory treated at a range of $80-90 \%$, when addressed at early stages.

New technologies with the combination of some machines that are able to produce two wavelengths are likely to optimise the treatment results. Enhancement in epidermal protection methods, such as cooling devices ${ }^{[82]}$, in order to minimise risk of thermal injury and pigmentation disorders will further allow a better outcome to be obtained even for darker skin types. Progress in the field of supplementary treatments (ß-blockers and chemotherapy drugs) are expected to further improve both the effectiveness and safety of these treatment methods in the near future.

To conclude, modern applications of lasers in dermatology constitute one of the most promising methods for the management of cutaneous vascular lesions, combining the advantages of invasive therapy with the safety of non-invasive therapy, while in certain cases lasers are the only way to treat these lesions. The continuous research on laser application for the treatment of the various types of vascular lesions - both congenital and acquired - and the combination of the existing systems guarantee particularly good results, as long as they are applied by specialised and experienced dermatologists. Careful assessment of the history of the lesion, the skin type, and the tissue response will enable the design of an individualised treatment protocol aiming for the best outcome.

\section{Conflict of interest}

The authors declare no potential conflict of interest with respect to the research, authorship, and/or publication of this article.

\section{References}

1. Anderson RR, Parish JA. Selective photothermolysis: Precise microsurgery by selective absorption of pulsed radiation. Science 1983; 220(4596): 524-527. doi: 10.1126/science.6836297.

2. Adamič M, Troilius A, Adatto M, Drosner M, Dahmane R. 
Vascular lasers and IPLS: Guidelines for care from the European Society for laser Dermatology (ESLD). J Cosmet Laser Ther 2007; 9(2): 113-124. doi: 10.1080/14764170701280693.

3. Bruscino N, Bonan P, Cannarozzo G, Moretti S, Lotti T, et al. Laser use in infantile hemangiomas, when and how. Dermatol Ther 2012; 25(4): 314-321. doi: 10.1111/j.1529-8019.2012.01466.x.

4. Laser treatment for skin problems. Drug Ther Bull 2004; 42: 73-76. doi: 10.1136/dtb.2004.421073.

5. Scheibner A, Wheeland RG. Use of the argon-pumped tunable dye laser for port-wine stains in children. J Dermatol Surg Oncol 1991; 17(9): 735-739. doi: 10.1111/j.1524-4725.1991.tb03428.x.

6. Richter GT and Friedman AB. Hemangiomas and vascular malformations: Current theory and management. Int J Pediatr 2012; 2012: 645678. doi: 10.1155/2012/645678.

7. Léauté-Labrèze C, Prey S, Ezzedine K. Infantile haemangioma: Part 1. Pathophysiology, epidemiology, clinical features, life cycle and associated structural abnormalities. J Eur Acad Dermatol Venereol 2011; 25(11): 1245-1253. doi: 10.1111/j.1468-3083.2011.04102.x.

8. Stier MF, Glick SA, Hirsch RJ. Laser treatment of pediatric vascular lesions: Port wine stains and hemangiomas. J Am Acad Dermatol 2008; 58(2): 261-285. doi: 10.1016/j.jaad.2007.10.492.

9. Alster TS, Tanzi EL. Combined 595-nm and 1,064-nm laser irradiation of recalcitrant and hypertrophic portwine stains in children and adults. Dermatol Surg 2009; 35(6): 914-919. doi: 10.1111/j.1524-4725.2009.01155.x.

10. Cordisco MR. An update on lasers in children. Curr Opin Pediatr 2009; 21(4): 499-504. doi: 10.1097/MOP.0b 013e32832e084f.

11. Astner S, Anderson RR. Treating vascular lesions. Dermatol Ther 2005; 18(6): 267-281. doi: 10.1111/j.15 29-8019.2005.05025.x.

12. Railan D, Parlette EC, Uebelhoer NS, Rohrer TE. Laser treatment of vascular lesions. Clin Dermatol 2006; 24(1): 8-15. doi: 10.1016/j.clindermatol.2005.10.026.

13. Mariwalla K, Dover JS. The use of lasers in the pediatric population. Skin Therapy Lett 2005; 10(8): 7-9.

14. Landthaler M, Hohenleutner U. Laser therapy of vascular lesions. Photodermatol Photoimmunol Photomed 2006; 22(6): 324-332. doi: 10.1111/j.1600-0781.2006.00254.x.

15. Galeckas KJ. Update on lasers and light devices for the treatment of vascular lesions. Semin Cutan Med Surg 2008; 27(4): 276-284. doi: 10.1016/j.sder.2008.08.002.

16. Apfelberg DB, Maser MR, Lash H, Rivers J. The argon laser for cutaneous lesions. JAMA 1981; 245(20): 2073-2075. doi: 10.1001/jama.1981.03310450057027.
17. França K, Chacon A, Ledon J, Savas J, Izakovic J, et al. Lasers for cutaneous congenital vascular lesions: A comprehensive overview and update. Lasers Med Sci 2013; 28(4): 1197-1204. doi: 10.1007/s10103-012-1220-2.

18. Ulrich H, Bäumler W, Hohenleutner U, Landthaler M. Neodymium-YAG laser for hemangiomas and vascular malformations - Long term results. J Dtsch Dermatol Ges 2005; 3(6): 436-440. doi: 10.1111/j.1610-0387.20 05.05723.x.

19. Angiero F, Benedicenti S, Benedicenti A, Arcieri K, Bernè E. Head and neck hemangiomas in pediatric patients treated with endolesional 980-nm diode laser. Photomed Laser Surg 2009; 27(4): 553-559. doi: 10.1089/pho.2008.2362.

20. Chinnadurai S, Sathe NA, Surawicz T. Laser treatment of infantile hemangioma: A systematic review. Lasers Surg Med 2016; 48(3): 221-233. doi: 10.1002/lsm.22455.

21. Rizzo C, Brightman L, Chapas AM, Hale EK, Cantatore-Francis JL, et al. Outcomes of childhood hemangiomas treated with the pulsed dye laser with dynamic cooling: A retrospective chart analysis. Dermatol Surg 2009; 35(12): 1947-1954. doi: 10.1111/j.15 24-4725.2009.01356.x.

22. Woo SH, Ahn HH, Kim SN, Kye YC. Treatment of vascular skin lesions with the variable pulse $595 \mathrm{~nm}$ pulsed dye laser. Dermatol Surg 2006; 32(1): 41-48. doi: 10.1097/00042728-200601000-00007.

23. Kono T, Sakurai H, Groff WF, Chan HH, Takeuchi M, et al. Comparison study of a traditional pulsed dye laser versus a long-pulsed dye laser in the treatment of ly childhood hemangiomas. Lasers Surg Med 2006; 38(2): 112-115. doi: 10.1002/lsm.20257.

24. Kessels JP, Hamers ET, Ostertag JU. Superficial hemangioma: Pulsed dye laser versus wait-and-see. Dermatol Surg 2013; 39(3 Pt 1): 414-421. doi: 10.1111/dsu.12081.

25. Zhong S, Tao Y, Zhou J, Liu Y, Yao L, et al. Infantile hemangioma: Clinical characteristics and efficacy of treatment with the long-pulsed 1,064-nm neodymium-doped yttrium aluminum garnet laser in 794 Chinese patients. Pediatr Dermatol 2015; 32(4): 495-500. doi: 10.1111/pde. 12593.

26. Kaune KM, Lauerer P, Kietz S, Eich C, Thoms KM, et al. Combination therapy of infantile hemangiomas with pulsed dye laser and Nd:YAG laser is effective and safe. $\mathrm{J}$ Deutsch Dermatol Ges 2014; 12(6): 473-478. doi: 10.1111/ddg. 12354.

27. Cerrati EW, March TMO, Chung H, Waner M. Diode laser for the treatment of telangiectasias following hemangioma involution. Otolaryngol Head Neck Surg 2015; 152(2): 239-243. doi: 10.1177/0194599814559192. 
28. Reddy KK, Blei F, Brauer JA, Waner M, Anolik R, et al. Retrospective study of the treatment of infantile hemangiomas using a combination of propranolol and pulsed dye laser. Dermatol Surg 2013; 39(6): 923-933. doi: 10.1111/dsu. 12158 .

29. Willenberg T, Baumgartner I. Vascular birthmarks. VASA 2013; 37(1): 5-17. doi: 10.1024/0301-1526.37.1.5.

30. Mulliken JB, Glowacki J. Hemangiomas and vascular malformations in infants and children: A classification based on endothelial characteristics. Plast Reconstr Surg 1982; 69(3): 412-422. doi: 10.1097/00 006534-198203000-00002.

31. Gao K, Huang Z, Yuan KH, Zhang B, Hu ZQ. Side-by-side comparison of photodynamic therapy and pulsed-dye laser treatment of port-wine stain birthmarks. $\mathrm{Br}$ J Dermatol 2013; 168(5): 1040-1046. doi: 10.1111/bjd.12130.

32. Geronemus RG. Argon laser for the treatment of cutaneous lesions. Clin Dermatol 1995; 13(1): 55-58. doi: 10.1016/0738-081X(94)00027-Y.

33. Liu H, Dang Y, Chai X, Wang Z, Ma L, et al. Treatment of port-wine stains with the 595-nm pulsed dye laser: A pilot study in Chinese patients. Clin Exp Dermatol 2007; 32(6): 646-649. doi: 10.1111/j.1365-2230.2007.02517.x.

34. Faurschou A, Togsverd-Bo K, Zachariae C, Hædersdal M. Pulsed dye laser vs. intense pulsed light for port-wine stains: A randomized side-by-side trial with blinded response evaluation. Br J Dermatol 2009; 160(2): 359-364. doi: 10.1111/j.1365-2133.2008.08993.x.

35. Kono T, Groff WF, Sakurai H. Treatment of port wine stains with the pulse dye laser. Ann Plast Surg 2006; 56(4): 460-463. doi: 10.1097/01.sap.00 00201554.44010 .44 .

36. Yuan KH, Li Q, Yu WL, Huang Z. Photodynamic therapy in treatment of port wine stain birthmarks-Recent progress. Photodiagnosis Photodyn Ther 2009; 6(3-4): 189-194. doi: 10.1016/j.pdpdt.2009.08.001.

37. Chapas AM, Eickhorst K, Geronemus R. Efficacy of early treatment of facial port wine stains in newborns: A review of 49 cases. Lasers Surg Med 2007; (39)7: 563-568. doi: 10.1002/lsm.20529.

38. Kelly KM, Choi B, McFarlane S, Motosue A, Jung B, et al. Description and analysis of treatments for port-wine stain birthmarks. Arch Facial Plast Surg 2005; 7(5): 287-294. doi: 10.1001/archfaci.7.5.287.

39. Li L, Kono T, Groff WF, Chan HH, Kitazawa Y, et al. Comparison study of a long-pulse pulsed dye laser and a long-pulse pulsed alexandrite laser in the treatment of port-wine stains. J Cosmet Laser Ther 2008; 10(1): 12-15. doi: 10.1080/14764170701817023.

40. Izikson L, Nelson JS, Anderson RR. Treatment of hyper- trophic and resistant port wine stains with a $755 \mathrm{~nm}$ laser: A case series of 20 patients. Lasers Surg Med 2009; 41(6): 427-432. doi: 10.1002/lsm.20793.

41. Yang MU, Yaroslavsky AN, Farinelli WA, Flotte TJ, Rius-Diaz F, et al. Long-pulsed neodymium:yttriumaluminum-garnet laser treatment for port-wine stains. J Am Acad Dermatol 2005; 52(3): 480-490. doi: 10.1016/j.jaad.2004.10.876.

42. Jasim ZF, Handley JM. Treatment of pulsed dye laser-resistant port-wine stain birthmarks. J Am Acad Dermatol 2007; 57(4): 677-682. doi: 10.1016/j.ja ad.2007.01.019.

43. Xing L, Li D, Chen B, Dai Y, Wu W, et al. Enhancement of light absorption by blood to Nd:YAG laser using PEG-modified gold nanorods. Lasers Surg Med 2016; 48(8): 790-803. doi: 10.1002/1sm.22557.

44. Wenxin Yu, Ma G, Qiu Y, Chen H, Jin Y, et al. Why do port-wine stains (PWS) on the lateral face respond better to pulsed dye laser (PDL) than those located on the central face? J Am Acad Dermatol 2016; 74(3): 527-535. doi: 10.1016/j.jaad.2015.08.026.

45. Adamič M, Pavlović MD, Troilius Rubin A, Palmetun-Ekbäck M, Boixeda P. Guidelines of care for vascular lasers and intense pulse light sources from the European Society for Laser Dermatology. J Eur Acad Dermatol Venereol 2015; 29(9): 1661-1678. doi: 10.1111/jdv.13177.

46. Liu S, Yang C, Yang S, Wang Z, Luo D, et al. Topical application of 5-aminolevulinic acid followed by 595-nm pulsed dye laser irradiation for the treatment of recalcitrant port-wine stains: A primary study. J Cosmet Laser Ther 2012; 87(6): 189-192. doi: 10.3109/14764 172.2012.699677.

47. Sivarajan V, Maclaren WM, Mackay IR. The effect of varying pulse duration, wavelength, spot size, and fluence on the response of previously treated capillary vascular malformations to pulsed-dye laser treatment. Ann Plast Surg 2006; 57(1): 25-32. doi: 10.1097/01.sap.00 00208942.15897.15.

48. Zelickson BD. Mechanism of action of topical aminolevulinic acid. $2^{\text {nd }}$ ed. In: Goldman MP (editor). Photodynamic therapy. Philadelphia, PA: Saunders Elsevier; 2008. p. 1-9.

49. Babilas P, Landthaler M, Szeimies RM. Photodynamic therapy in dermatology. Eur J Dermatol 2006; 16(4): 340-348.

50. Qin ZP, Li KL, Li R, Liu XJ. Photodynamic therapy of port wine stains-A report of 238 cases. Photodiagnosis Photodyn Ther 2007; 4(1): 53-59. doi: 10.10 16/j.pdpdt.2007.01.001.

51. Qiu H, Gu Y, Wang Y, Huang N. Twenty years of clinical 
experience with a new modality of vascular-targeted photodynamic therapy for port wine stains. Dermatol Surg 2011; 37(11): 1603-1610. doi: 10.1111/j.1524-47 25.2011.02129.x.

52. Tournas JA, Lai J, Truitt A, Huang YC, Osann KE, et al. Combined benzoporphyrin derivative monoacid ring photodynamic therapy and pulsed dye laser for port wine stain birthmarks. Photodiagnosis Photodyn Ther 2009; 6(34): 195-199. doi: 10.1016/j.pdpdt.2009.10.002.

53. Alam M, Dover JS, Arndt KA. Treatment of facial telangiectasia with variable-pulse high-fluence pulsed-dye laser: Comparison of efficacy with fluences immediately above and below the purpura threshold. Dermatol Surg 2003; 29(7): 681-684. doi: 10.1097/00042728-20 0307000-00001.

54. Nymann P, Hedelund L, Hædersdal M. Long-pulsed dye laser vs. intense pulsed light for the treatment of facial telangiectasias: A randomized controlled trial. J Eur Acad Dermatol Venereol 2010; 24(2): 143-146. doi: 10.11 11/j.1468-3083.2009.03357.x.

55. Clark C, Cameron H, Moseley H, Ferguson J, Ibbotson SH. Treatment of superficial cutaneous vascular lesions: Experience with the KTP $532 \mathrm{~nm}$ laser. Lasers Med Sci 2004; 19(1): 1-5. doi: 10.1007/s10103-004-0294-x.

56. Ozyurt K, Colgecen E, Baykan H, Ozturk P, Ozkose M. Treatment of superficial cutaneous vascular lesions: Experience with the long-pulsed $1064 \mathrm{~nm} \mathrm{Nd}$ :Yag laser. ScientificWorldJournal 2012; 2012: 197139. doi: 10.1100/2012/197139.

57. Rose AE, Goldberg DJ. Successful treatment of facial telangiectasias using a micropulse 1,064-nm neodymium-doped yttrium aluminum garnet laser. Dermatol Surg 2013; 39(7): 1062-1066. doi: 10.1111/dsu.12185.

58. Bäumler W, Ulrich H, Hartl A, Landthaler M, Shafirstein G. Optimal parameters for the treatment of leg veins using Nd:Yag lasers at $1064 \mathrm{~nm}$. Br J Dermatol 2006; 155(2): 364-371. doi: 10.1111/j.1365-2133.2006.07 314.x.

59. Athavale SM, Ries WR, Carniol PJ. Laser treatment of cutaneous vascular tumors and malformations. Facial Plast Surg Clin North Am 2011; 19(2): 303-312. doi: 10.1016/j.fsc.2011.05.009.

60. Srinivas CR, Kumaresan M. Lasers for vascular lesions: Standard guidelines of care. Indian J Dermatol Venereol Leprol 2011; 77(3): 349-368. doi: 10.4103/0378-63 23.79728.

61. Bevin AA, Parlette EC, Yacov D, Ross EV. Variable pulse $\mathrm{Nd}$ :YAG laser in the treatment of facial telangiectasias. Dermatol Surg 2006; 32(1): 7-12. doi: 10.10 97/00042728-200601000-00002.
62. Meesters AA, Pitassi LHU, Campos V, Wolkerstorfer A, Dierickx CC. Transcutaneous laser treatment of leg veins. Lasers Med Sci 2014; 29(2): 481-492. doi: 10.1007/s10103-013-1483-2.

63. Bernstein EF, Kligman A. Rosacea treatment using the new-generation, high-energy, $595 \mathrm{~nm}$, long pulse-duration pulsed-dye laser. Lasers Surg Med 2008; 40(4): 233-239. doi: 10.1002/lsm.20621.

64. Menezes N, Moreira A, Mota G, Baptista A. Quality of life and rosacea: Pulsed dye laser impact. J Cosmet Laser Ther 2009; 11(3): 139-141. doi: 10.1080/147 64170902741311.

65. Jasim ZF, Woo WK, Handley JM. Long-pulsed (6-ms) pulsed dye laser treatment of rosacea-associated telangiectasia using subpurpuric clinical threshold. Dermatol Surg 2004; 30(1): 37-40.

66. Shim TN, Abdullah A. The effect of pulsed dye laser on the dermatology life quality index in erythematotelangiectatic rosacea patients: An assessment. J Clin Aesthet Dermatol 2013; 6(4): 30-32.

67. Mark KA, Sparacio RM, Voigt A, Marenus K, Sarnoff DS. Objective and quantitative improvement of rosacea-associated erythema after intense pulsed light treatment. Dermatol Surg 2003; 29(6): 600-604.

68. Hu SW, Chu J, Meehan S, Kamino H, Pomeranz MK. Acquired brachial cutaneous dyschromatosis. Dermatol Online J 2011; 17(10): 16.

69. Meijs MM, Blok FAA, De Rie MA. Treatment of Poikiloderma of Civatte with the pulsed dye laser: A series of patients with severe depigmentation. J Eur Acad Dermatol Venereol 2006; 20(10): 1248-1251. doi: 10.1111/j.1468-3083.2006.01782.x.

70. Tierney EP, Hanke CW. Treatment of Poikiloderma of Civatte with ablative fractional laser resurfacing: Prospective study and review of the literature. J Drugs Dermatol 2009; 8(6): 527-534

71. Bencini PL, Tourlaki A, De Giorgi V, Galimberti M. Laser use for cutaneous vascular alterations of cosmetic interest. Dermatol Ther 2012; 25(4): 340-351. doi: 10.1111/j.1529-8019.2012.01463.x.

72. Sivarajan V, Al Aissami M, Maclaren W, Mackay IR. Recurrence of spider naevi following treatment with 585 nm pulsed dye laser. J Plast Reconstr Aesthet Surg 2007; 60(6): 668-671. doi: 10.1016/j.bjps.2006.10.012.

73. Neville BW, Damn DD, Allen CM, Bouquot JE. Oral and maxillofacial pathology. 2nd ed. Philadelphia, PA: WB Saunders; 2002. p. 437-495.

74. Ting PT, Rao J. Vascular lesions. In: Bogdan Allemann I, Goldberg DJ (editors). Basics in dermatological laser applications. Curr Probl Dermatol 2011; 42: 67-80. doi: 
$10.1159 / 000328264$.

75. González S, Vibhagool C, Falo Jr LD, Momtaz KT, Grevelink $\mathrm{J}$, et al. Treatment of pyogenic granulomas with the $585 \mathrm{~nm}$ pulsed dye laser. J Am Acad Dermatol 1996; 35(3): 428-431. doi: 10.1016/S0190-9622(96)90 610-6.

76. Bédard MS, Boulanger J. Treatment of lobular capillary hemangioma with the Nd:YAG laser: Retrospective case series of 25 patients. J Cutan Med Surg 2009; 13(3): 181-182. doi: 10.2310/7750.2008.08053.

77. Lindenmüller IH, Noll P, Mameghani T, Walter C. CO2 laser-assisted treatment of a giant pyogenic granuloma of the gingiva. Int J Dent Hyg 2010; 8(3): 249-252. doi: 10.1111/j.1601-5037.2010.00449.x.

78. Akamatsu T, Hanai U, Kobayashi M, Miyasaka M. Pyogenic granuloma: A retrospective 10-year analysis of 82 cases. Tokai J Exp Clin Med 2015; 40(3): 110-114.
79. Bekhor PS. Long-pulsed Nd:YAG laser treatment of venous lakes: Report of a series of 34 cases. Dermatol Surg 2006; 32(9): 1151-1154. doi: 10.1097/00042728-200 609000-00007.

80. Roncero M, Cañueto J, Blanco S, Unamuno P, Boixeda P. Multiwavelength laser treatment of venous lakes. Dermatol Surg 2009; 35(12): 1942-1946. doi: 10.1111/j.1524-4725.2009.01357.x.

81. Azevedo LH, Galletta VC, Eduardo CdeP, Migliari DA. Venous lake of the lips treated using photocoagulation with high-intensity diode laser. Photomed Laser Surg 2010; 28(2): 263-265. doi: 10.1089/pho.2009.2564.

82. Raulin C, Greve B, Hammes S. Cold air in laser therapy: First experiences with a new cooling system. Lasers Surg Med 2000; 27(5): 404-410. doi: 10.1002/1096-9101(200 0)27:5<404::AID-LSM1001>3.0.CO;2-S. 